\title{
Escritura de la historia, representaciones y usos del pasado en argentina
}

Este número de Estudios, inspirado originalmente en una propuesta de la Dra. Marta Philp, enlaza con el debate intelectual acerca de la relación entre conocimiento histórico y poder político, entre historia profesional e historias militantes, entre metodologías académicas y memorias colectivas. En el siglo XX, la historiografía tradicional, ceñida a la recolección y selección de datos, fue concebida como un brazo auxiliar del Estado y de gobiernos de distinto signo con fines de legitimación. Así, las juntas provinciales y municipales de Historia suministraron oportunamente los datos necesarios para poner nombres a calles y plazas, erigir monumentos y celebrar conmemoraciones. La invención de una tradición patria o la forja de un esencialísimo «ser nacional» descansaron en esa función legitimadora de la historia. Su corolario fue, muchas veces, el desarrollo de una disciplina que rendía culto al poder -gobernadores e intendentes, presidentes, obispos y generales-, incapaz de construir problemas teóricos a partir de interrogantes y formular hipótesis de trabajo. Esta perspectiva redujo a muchos historiadores a ser una suerte de escribanos de pasado o, peor aún, a ser lo que metafóricamente podemos denominar «los escribas del rey».

En una obra política de un célebre revolucionario de principios del siglo XX - ¿Qué hacer? (1902)- Vladimir Ilyich Lenin distinguía la agitación de la propaganda. La primera suponía transmitir consignas, pocas ideas (en general denuncias) a mucha gente con el fin de impulsar la acción colectiva. Su función era lograr «un efecto terriblemente excitante» que moviera al reclamo social. La propaganda, en cambio, implicaba difundir un conjunto de ideas interrelacionadas entre sí con el fin de suministrar una explicación más profunda y compleja a un número menor de personas. La tarea del historiador no es ni la una ni la otra, so pena de incurrir en la «historia militante», situada en las antípodas de la historiografía tradicional en la medida que desafía el statu quo, pero incapaz de pensar e identificar las verdades relativas, tornasoladas y poliédricas presentes en personajes históricos, actores políticos y fenómenos sociales. 
El presente número de Estudios cuenta con un puñado de aportes especialmente relevantes para pensar estos y otros problemas que escapan a la presente introducción. Hilda Sabato, recientemente galardonada por el Ministerio de Ciencia, Tecnología e Innovación de la Nación con el premio Bernardo Houssay 2020 en el área de las ciencias humanas, ofrece una reflexión sobre la producción historiográfica desde 1984 hasta el presente. Fernando Devoto, premio Konex en Historia (2004), rescata del olvido las contribuciones de Haydée Gorostegui de Torres en la nueva historiografía de los años sesenta. La doctora Marta Philp (CEAFCS-FFyH-UNC), centró su interés en dos historiadores íntimamente vinculados a Córdoba: Waldo Ansaldi y Guillemo Beato, en el marco de la convulsionada inestabilidad política de esa década y los años que siguieron. Marcela Ternavasio, investigadora del CONICET y de la Universidad Nacional de Rosario, trabaja en torno a los dilemas interpretativos planteados por Rosas y el rosismo, un período controversial y a la vez dominado por un líder político cuyo nombre propio marcó toda una época. Leandro Pankonin (Universidad Nacional de General Sarmiento y becario del CONICET) aporta en relación a esta temática, las representaciones de Rosas en la música de la primera mitad del siglo XX.

Otros cuatro trabajos relevantes completan esta entrega: Maria Silvia Leoni, directora del Doctorado en Historia de la Universidad Nacional del Nordeste, estudia las representaciones del pasado en Chaco durante la primera mitad del siglo XX desde una perspectiva de análisis interesada en desentrañar su papel de cara a la construcción de identidades colectivas, de orden regional y provincial. La doctora Estela Spinelli, destacada docente e investigadora de la Universidad Nacional del Centro de la provincia de Buenos Aires, centró su aporte en la interpretación de las explicaciones ofrecidas desde las ciencias sociales para comprender el fracaso del gobierno peronista entre 1973-76. Federico Lorenz (UBA-CONICET) ofrece una original reflexión sobre las intervenciones públicas de los historiadores, en especial aquellas que exceden el campo de las publicaciones eruditas y las discusiones entre pares. Finalmente, Agustín Rojas, doctor en Historia por la Universidad Nacional de Córdoba, analiza las correlaciones entre autoritarismo militar y desarrollo de la historia como disciplina científica a partir de la experiencia del CONICET, durante la última dictadura (1976-1983).

Este volumen se cierra, como es de rigor, con cuatro comentarios bibliográficos, elaborados por Cristina Viano (Universidad Nacional de Rosario), Angélica Pineda Silva (Universidad Autónoma Metropolitana 
Unidad Xochimilco, México), Carlos Joan Ghigliazza (Universidad Nacional de Mar del Plata) y Mairaya Almaguer López (Universidad Nacional de La Plata).

Finalmente, queremos dedicar este número a la memoria de la gran historiadora de Rosario, Marta Bonaudo, investigadora principal del CONICET y profesora del Centro de Estudios Avanzados, recientemente fallecida.

\author{
Cesar Tcach \\ Director de Estudios
}

